\title{
A Mass Spectrometry Study of Alkanes in Air Plasma at Atmospheric Pressure
}

\author{
Ester Marotta and Cristina Paradisi \\ Dipartimento di Scienze Chimiche, Università di Padova, Padova, Italy
}

The positive APCI-mass spectra in air of linear (n-pentane, $n$-hexane, $n$-heptane, $n$-octane), branched [2,4-dimethylpentane, 2,2-dimethylpentane and 2,2,4-trimethylpentane (i-octane)], and cyclic (cyclohexane) alkanes were analyzed at different mixing ratios and temperatures. The effect of air humidity was also investigated. Complex ion chemistry is observed as a result of the interplay of several different reagent ions, including atmospheric ions $\mathrm{O}_{2}^{+}{ }^{+}, \mathrm{NO}^{+}$, $\mathrm{H}_{3} \mathrm{O}^{+}$, and their hydrates, but also alkyl fragment ions derived from the alkanes. Some of these reactions are known from previous selected ion/molecule reaction studies; others are so far unreported. The major ion formed from most alkanes (M) is the species $[\mathrm{M}-\mathrm{H}]^{+}$, which is accompanied by $\mathrm{M}^{+}$only in the case of $n$-octane. Ionic fragments of $\mathrm{C}_{n} \mathrm{H}_{2 n+1}{ }^{+}$composition are also observed, particularly with branched alkanes: the relative abundance of such fragments with respect to that of $[\mathrm{M}-\mathrm{H}]^{+}$decreases with increasing concentration of $\mathrm{M}$, thus suggesting that they react with $\mathrm{M}$ via hydride abstraction. The branched $\mathrm{C}_{7}$ and $\mathrm{C}_{8}$ alkanes react with $\mathrm{NO}^{+}$to form a $\mathrm{C}_{4} \mathrm{H}_{10} \mathrm{NO}^{+}$ion product, which upon collisional activation dissociates via $\mathrm{HNO}$ elimination. The structure of $t-\mathrm{Bu}^{+}(\mathrm{HNO})$ is proposed for such species, which is reasonably formed from the original $\mathrm{NO}^{+}(\mathrm{M})$ ion/molecule complex via hydride transfer and olefin elimination. Finally, linear alkanes $C_{5}-C_{8}$ give a product ion corresponding to $\mathrm{C}_{4} \mathrm{H}_{7}{ }^{+}(\mathrm{M})$, which we suggest is attributed to addition of $[\mathrm{M}-\mathrm{H}]^{+}$to $\mathrm{C}_{4} \mathrm{H}_{8}$ olefin formed in the charge-transfer-induced fragmentation of $\mathrm{M}$. The results are relevant to applications of nonthermal plasma processes in the fields of air depuration and combustion enhancement. (J Am Soc Mass Spectrom 2009, 20, 697-707) @ 2009 Published by Elsevier Inc. on behalf of American Society for Mass Spectrometry

$\mathrm{A}$ tmospheric (or nonthermal) plasmas are gaining increasing importance in different fields of application ranging from material technology to environmental pollution control [1]. Research and development are very active in this latter field, which comprises not only air [2,3] but, more recently, also water treatment processes [4]. For air pollution control, different types of reactors and power supplies are being developed and tested for production of nonthermal plasmas by means of electrical discharges [3]. Following an initial phase devoted to prove the feasibility and competitiveness of the process in terms of energy and cost efficiency, research is presently focusing on the characterization of the chemistry-i.e., the products being released and the underlying chemical mechanisms-to develop a more efficient and cleaner process [5].

In nonthermal plasmas, which are conveniently produced by electric corona discharges in air at atmospheric pressure, high-energy electrons induce ionization, excitation, and dissociation of the bulk gas molecules, $\mathrm{N}_{2}$ and $\mathrm{O}_{2}$. The resulting reactive species, ionic and neutral as well as thermalized electrons, can attack molecules of organic pollutants present in the air,

Address reprint requests to Prof. Cristina Paradisi, University of Padova, Department of Chemical Sciences, Via Marzolo 1, 35131 Padova, Italy. E-mail: cristina.paradisi@unipd.it such as hydrocarbons and other volatile organic compounds (VOCs), and initiate a chain of reactions leading eventually to their oxidation. It is generally accepted that nonthermal plasma-induced VOC oxidation proceeds via VOC-derived organic radicals, $\mathrm{R}^{\bullet}$, which are trapped by molecular oxygen and undergo further reactions as described for their tropospheric oxidation [6], leading eventually to $\mathrm{CO}_{2}$. As for the origin of such VOC-derived radicals, i.e., the nature of the initiation steps of nonthermal plasma-induced VOC decay, reactions of VOC molecules with neutrals and radicals, notably $\mathrm{O}\left({ }^{3} \mathrm{P}\right)$ and ${ }^{\bullet} \mathrm{OH}$, are usually envisioned. However, increasing numbers of literature reports suggest that in some cases ionic initiation steps might prevail [7-12]. A major involvement of ions in nonthermal plasma chemistry is to be expected since gas-phase ion/molecule reactions are usually orders of magnitude faster than radical/molecule reactions.

We have long been interested in the role played by ionic intermediates and ionic reactions in the nonthermal plasma-induced oxidation of VOCs and have used atmospheric-pressure chemical ionization mass spectrometry (APCI-MS) to detect and study the ions that are produced by corona discharges in VOC-contaminated air $[9,12,13]$.

Saturated hydrocarbons are ideal VOC models because of their environmental relevance and the wealth
(C) 2009 Published by Elsevier Inc. on behalf of American Society for Mass Spectrometry. $1044-0305 / 09 / \$ 32.00$

doi:10.1016/j.jasms.2008.12.005
Published online December 13, 2008 Received October 2, 2008 Revised December 9, 2008 Accepted December 9, 2008 
of available data concerning their oxidation and combustion. Recently we investigated the plasma-induced decomposition of two alkanes, $n$-hexane and $i$-octane, both important gasoline components, under the effect of corona discharges of different types (pulsed and DC) and polarities (positive and negative) in air at room temperature and atmospheric pressure [14-16]. The results of APCI-MS ion analysis beautifully explained the observed current/voltage profiles and revealed that, in spite of the rather similar general features (both the efficiencies and product distributions of $+\mathrm{DC}$ and $-\mathrm{DC}$ processes are not greatly different), the crucial initiation steps are different in the two cases. With -DC corona radical initiation steps occur, involving mainly $\mathrm{O}\left({ }^{3} \mathrm{P}\right)$ in dry air and ${ }^{\circ} \mathrm{OH}$ in humid air. With + DC corona ionic reactions prevail not only in dry air but also in humid air [16]. It was therefore of interest to study the ion chemistry of such systems in greater detail and also to extend the investigation to other alkanes and plasma conditions.

The reactions of hydrocarbons with major ions in air plasma, notably $\mathrm{O}_{2}{ }^{+} \cdot \mathrm{NO}^{+}$, and $\mathrm{H}_{3} \mathrm{O}^{+}$and their hydrates, each mass selected, have been extensively studied under different pressures. It was found that $\mathrm{O}_{2}{ }^{+}$ reacts mainly by dissociative or nondissociative charge transfer [17-19], $\mathrm{NO}^{+}$by hydride abstraction [18-22], and $\mathrm{H}_{3} \mathrm{O}^{+}$by association $[19,22]$. Moreover, there are a few reports on the APCI-MS and ion mobility spectrometry (IMS) of alkanes, alkenes, and cycloalkanes in air $[23,24]$. However, to the best of our knowledge there are no comprehensive studies on the ion chemistry in a plasma generated by corona discharges in hydrocarbon-doped air. The results of selected ion/molecule reactions and of previous APCI studies served as important guides to help interpret the data reported here.

Another good reason for studying the ion chemistry of hydrocarbons in nonthermal air plasmas is its relevance to one emerging area of research and development dealing with the application of nonthermal plasmas to combustion enhancement [25]. Specific targets of plasma-assisted combustion are the improvement of ignition of combustible mixtures, the increase of combustion efficiency, and the improvement of combustion stability, for both the enhancement of combustion uniformity and the reduction of pollutant emissions. In one interesting approach, combustion occurs away from the plasma region, thereby providing more insight into the role played by plasma chemistry [26, 27]. Specifically, nonthermal plasmas decompose fuel-gas hydrocarbons (methane, ethane, propane, and butane) into smaller more easily combusted hydrocarbons (fuel cracking) and into highly reactive species (e.g., radicals) that can help propagate combustion reactions (fuel activation). Since plasma-induced fuel cracking and fuel activation result from electron-molecule and ion-molecule interactions, a comprehensive mass spectrometric study of the ion chemistry of hydrocarbons in air plasmas is highly desirable.
We report and discuss here the results of a study of the positive-ion chemistry observed in the nonthermal plasma produced by corona discharge in air contaminated by several linear and branched $\mathrm{C}_{5}-\mathrm{C}_{8}$ alkanes and by cyclohexane.

\section{Experimental}

\section{Materials}

All hydrocarbons examined were commercial R.P. product of Aldrich Chemical (purity 97-99\%; Milwaukee, WI, USA) and were used as received. High-purity synthetic air, with a specified $\mathrm{H}_{2} \mathrm{O}$ impurity of $<3$ ppm, was used as buffer gas.

\section{Instrumentation and Procedures}

APCI spectra of alkanes in air plasma were obtained using a TRIO 1000 II quadrupole instrument (Fisons Instruments, Manchester, UK), equipped with a Fisons APCI source. Schematics of this source and of the experimental setup used for the introduction of vaporized samples were given previously [9]. The ion source is kept at near atmospheric pressure by flowing a stream of synthetic air at $4000-5000 \mathrm{~mL} \mathrm{m^{-1 }}$ introduced through the nebulizer line, a capillary of approximately $2 \mathrm{~mm}$ i.d. The final length $(\sim 1 \mathrm{~cm})$ of the nebulizer line is wrapped externally with a heating wire, which controls the temperature of the APCI source. The liquid alkanes are introduced as vapors stripped from a small reservoir by an auxiliary flow of buffer gas. Depending on the specific hydrocarbon and the temperature, this flow is adjusted to set values

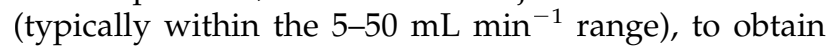
the desired concentration (typically within the 10-1000 $\mathrm{ppm}_{\mathrm{v}}$ range) of the alkane in the APCI source. Two such lines are available on this instrument and merge into a capillary (i.d. $=0.3 \mathrm{~mm}$ ) that enters the APCI source running coaxially inside the nebulizer line. In some experiments, the second line was used for introducing $\mathrm{H}_{2} \mathrm{O}$ or deuterated water $\left(\mathrm{D}_{2} \mathrm{O}\right)$ vapor into the source.

The needle electrode for corona discharge was kept at $3000 \mathrm{~V}$. Ions leave the source through an orifice nearly $50 \mu \mathrm{m}$ in diameter in the counter electrode (the "sampling cone," held at $0-150 \mathrm{~V}$ relative to ground), cross a region pumped down to roughly $10^{-2}$ Torr and, through the orifice in a second conical electrode (the "skimmer cone," kept at ground potential), reach the low-pressure region hosting the focusing lenses and the quadrupole analyzer. It was shown earlier that collision-induced dissociation (CID) experiments can be conducted in the intermediate pressure region between sampling and skimmer cones by the proper adjustment of $\mathrm{V}_{\text {cone, }}$ the difference between their potentials [9]. In our experiments spectra were recorded at several different values of $\mathrm{V}_{\text {cone, }}$ ranging from the lowest possible value $(1-5 \mathrm{~V})$ necessary to achieve an acceptable signalto-noise ratio, up to $150 \mathrm{~V}$, thus providing energy- 

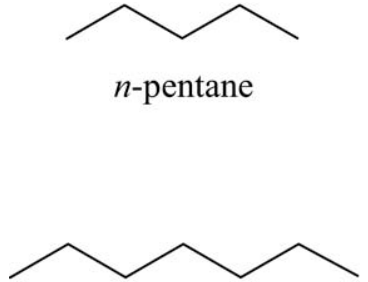

$n$-heptane

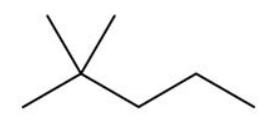

2,2-dimethylpentane

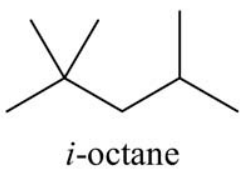

$i$-octane
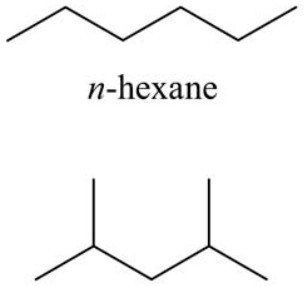

2,4-dimethylpentane
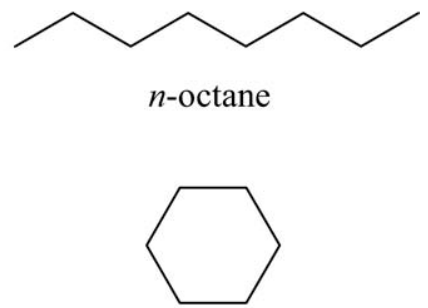

cyclohexane
Scheme 1

resolved mass spectral data. Each experiment also included, before the introduction of the alkane, a preliminary analysis of the background spectra with only air introduced into the APCI source, again at several different values of $\mathrm{V}_{\text {cone. }}$. For any given $\mathrm{V}_{\text {cone }}$ setting, spectra were acquired for $1 \mathrm{~min}$ and averaged. In the output spectra the averaged ion current is reported in the top right-hand corner (Scan AP+). Before conducting an experiment at $300{ }^{\circ} \mathrm{C}$, the nebulizer was kept at $300-400{ }^{\circ} \mathrm{C}$ for a couple of hours and the inlet lines were heated with the help of a heating gun.

\section{Results}

The APCI mass spectra in air of the hydrocarbons listed in Scheme $\mathbf{1}$ were investigated as a function of $\mathrm{V}_{\text {cone }}$ at two temperatures, 30 and $300{ }^{\circ} \mathrm{C}$, and at different mixing ratios in air. Also investigated was the effect of the humidity in the air. Preliminary experiments were conducted in the absence of hydrocarbons to acquire, under the various conditions explored in this study, APCI "background" spectra in pure air plasma. Such spectra were the same as observed and described in detail in previous studies [9] and are reported in the Supplementary Material (Figure S1, which can be found in the electronic version of this article). Briefly, the primary ions produced by positive corona discharge in air (e.g., $\mathrm{N}_{2}{ }^{+\bullet}$ and $\mathrm{O}_{2}{ }^{+}$) ) are not detected because they are quantitatively converted via highly efficient exothermic ion/molecule reactions into hydrates of the hydronium ion, $\mathrm{H}_{3} \mathrm{O}^{+}\left(\mathrm{H}_{2} \mathrm{O}\right)_{n}$, which are the major "background" positive ions. The cluster size distribution depends on the APCI source temperature and on the amount of residual humidity in the apparatus: typically at $30{ }^{\circ} \mathrm{C}$ and at low values of $\mathrm{V}_{\text {cone }}$ complexes with $n=2,3$, and 4 are detected, the most abundant being usually $\mathrm{H}_{3} \mathrm{O}^{+}\left(\mathrm{H}_{2} \mathrm{O}\right)_{3}$. Other ions observed, although in lower abundance, are the hydrates $\mathrm{NO}^{+}\left(\mathrm{H}_{2} \mathrm{O}\right)_{n}$, with $n=1-3$. At higher source temperatures $\left(300{ }^{\circ} \mathrm{C}\right)$ the same "background" ions are observed but of smaller cluster size. At any given source temperature, increasing $\mathrm{V}_{\text {cone }}$ results in ion declustering as a consequence of CID, eventually producing the bare $\mathrm{H}_{3} \mathrm{O}^{+}$and $\mathrm{NO}^{+}$ ions. At yet higher voltages $\left(\mathrm{V}_{\text {cone }} \geq 90-100 \mathrm{~V}\right)$ new signals appear at $m / z 29,32$, and 33 attributed to $\mathrm{N}_{2} \mathrm{H}^{+}$, $\mathrm{O}_{2}{ }^{+} \cdot$, and $\mathrm{O}_{2} \mathrm{H}^{+}$, respectively, formed in endothermic ion/molecule reactions [9].

Addition of a hydrocarbon, even in trace amounts, produces dramatic changes in the plasma ion population as a result of the efficient exothermic ion/molecule reactions with the "background" ions. In the following paragraphs behaviors of each hydrocarbon compound are briefly described.

\section{n-Pentane}

Positive APCI spectra of $n$-pentane $(\mathrm{M})$ recorded at $300{ }^{\circ} \mathrm{C}$ and at different values of $\mathrm{V}_{\text {cone }}$ are shown in Figure 1. At low $\mathrm{V}_{\text {cone }}$ values (Figure 1a), the spectrum

(a)

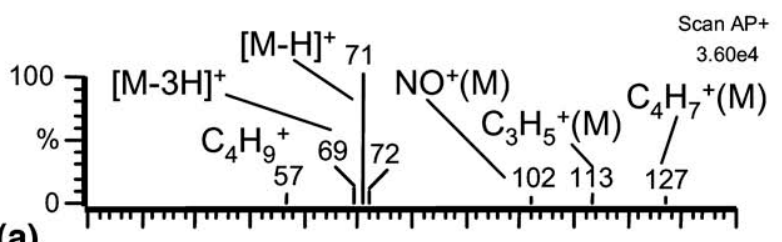

(b)
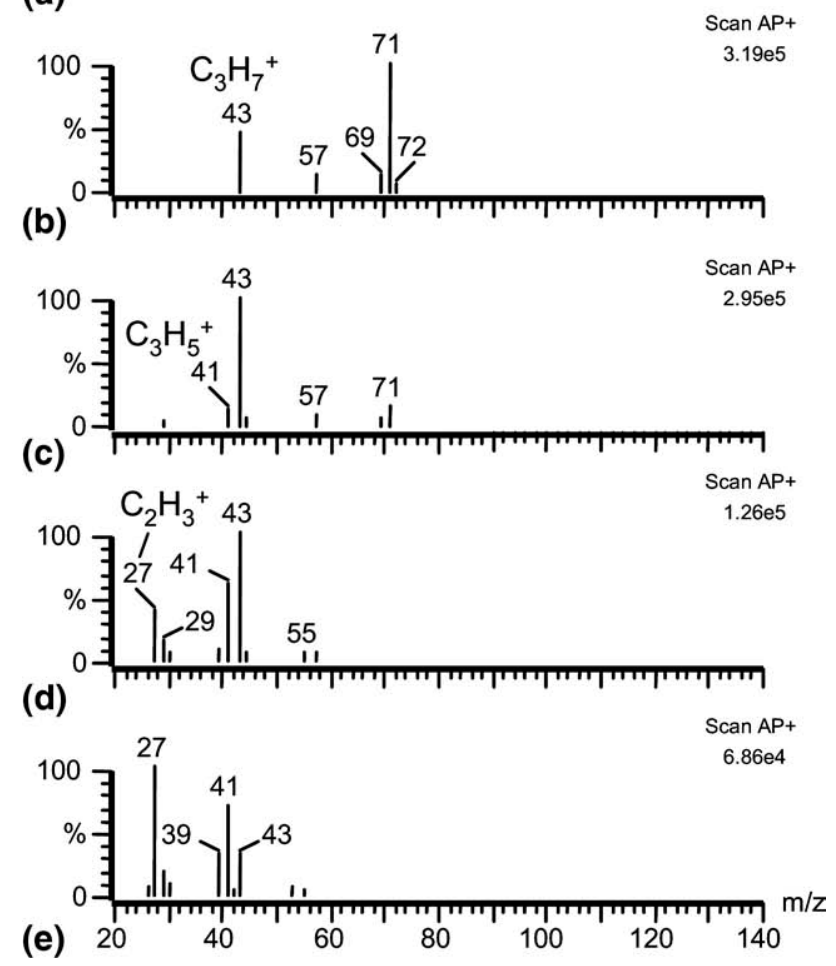

Figure 1. Positive APCI spectra of $n$-pentane in synthetic air at $300{ }^{\circ} \mathrm{C}$ and values of $\mathrm{V}_{\text {cone }}$ of (a) $1 \mathrm{~V}$, (b) $30 \mathrm{~V}$, (c) $50 \mathrm{~V}$, (d) $70 \mathrm{~V}$, (e) $90 \mathrm{~V}$. 
is dominated by a signal at $m / z 71$ ascribed to $\mathrm{C}_{5} \mathrm{H}_{11}{ }^{+}$, i.e., $[\mathrm{M}-\mathrm{H}]^{+}$. Additional signals of low intensity are ascribed to $\mathrm{C}_{5} \mathrm{H}_{9}{ }^{+}\left([\mathrm{M}-3 \mathrm{H}]^{+}\right)(m / z 69), \mathrm{C}_{4} \mathrm{H}_{9}{ }^{+}(m / z 57)$, and to ion/molecule complexes $\mathrm{NO}^{+}(\mathrm{M})(\mathrm{m} / \mathrm{z}$ 102), $\mathrm{C}_{3} \mathrm{H}_{5}{ }^{+}(\mathrm{M})(\mathrm{m} / z \mathrm{z} 113)$, and $\mathrm{C}_{4} \mathrm{H}_{7}{ }^{+}(\mathrm{M})(\mathrm{m} / z$ 127). Similar results were obtained at $30{ }^{\circ} \mathrm{C}$ except for the absence of the ion/molecule complex $\mathrm{NO}^{+}(\mathrm{M})(\mathrm{m} / z$ 102). The attribution of the signal at $\mathrm{m} / \mathrm{z} 127$ to a species of $\mathrm{C}_{4} \mathrm{H}_{7}{ }^{+}(\mathrm{M})$ composition rather than $\mathrm{H}_{3} \mathrm{O}^{+}(\mathrm{M})\left(\mathrm{H}_{2} \mathrm{O}\right)$ is consistent with the observation that no mass displacement of the $\mathrm{m} / \mathrm{z} 127$ signal occurred when $\mathrm{D}_{2} \mathrm{O}$ was admitted into the ion source (Figure S2 in the Supplementary Material).

The concentration of $n$-pentane does not appear to influence significantly the relative abundances of the various ionic species observed in the plasma.

As $\mathrm{V}_{\text {cone }}$ is increased, the fragmentation of $[\mathrm{M}-\mathrm{H}]^{+}$ takes place, giving product ions $\mathrm{C}_{3} \mathrm{H}_{7}{ }^{+}(\mathrm{m} / z$ 43) and $\mathrm{C}_{3} \mathrm{H}_{5}{ }^{+}\left(\mathrm{m} / z\right.$ 41) by ethylene loss followed by $\mathrm{H}_{2}$ loss (Figure $1 \mathrm{~b}$ and $\mathrm{c}$ ). At yet higher $\mathrm{V}_{\text {cone }}$ values propene loss from $[\mathrm{M}-\mathrm{H}]^{+}$prevails with the formation of $\mathrm{C}_{2} \mathrm{H}_{3}{ }^{+}(\mathrm{m} / \mathrm{z} 27)$ (Figure 1d and e).

\section{n-Hexane}

The general features of the positive APCI spectra of $n$-hexane are similar to those of $n$-pentane. At $300{ }^{\circ} \mathrm{C}$ and at low $\mathrm{V}_{\text {cone }}$ values, the signal attributed to $\mathrm{C}_{6} \mathrm{H}_{13}{ }^{+}$, i.e., $[\mathrm{M}-\mathrm{H}]^{+}(\mathrm{m} / \mathrm{z} 85)$, is the base peak of the spectrum, whereas $[\mathrm{M}-3 \mathrm{H}]^{+}(\mathrm{m} / \mathrm{z}$ 83) and shorter chain alkyl cations, $\mathrm{C}_{4} \mathrm{H}_{9}{ }^{+}\left(\mathrm{m} / \mathrm{z}\right.$ 57) and $\mathrm{C}_{5} \mathrm{H}_{11}{ }^{+}(\mathrm{m} / \mathrm{z} 71)$, form in low abundance (Figure 2a). No significant temperature effects are observed except that, as for $n$-pentane, the ion/molecule complex $\mathrm{NO}^{+}(\mathrm{M})(\mathrm{m} / \mathrm{z} 116)$ is never de-

(a)

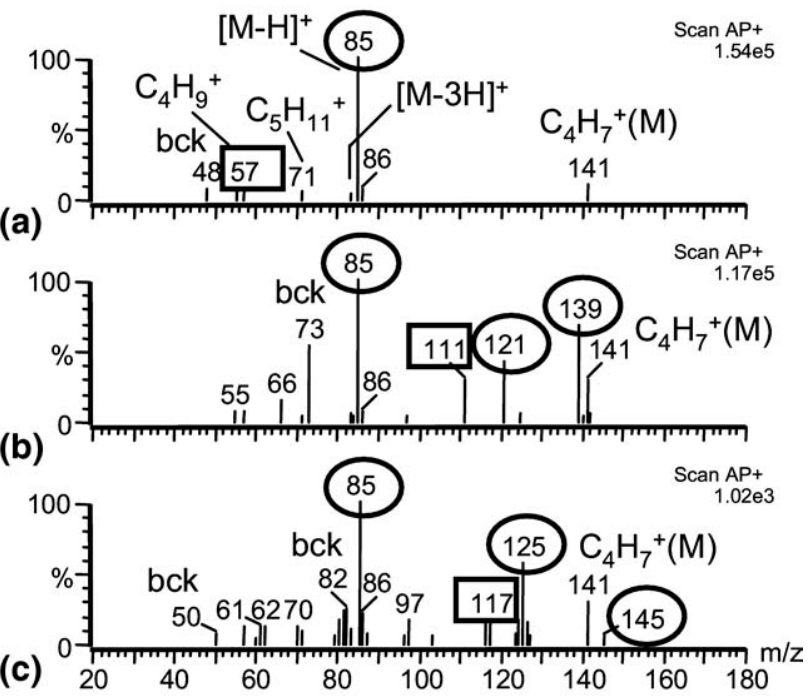

Figure 2. Positive APCI spectra of $n$-hexane at $300{ }^{\circ} \mathrm{C}$ and $\mathrm{V}_{\text {cone }}=1 \mathrm{~V}(\mathbf{a})$ in dry air, (b) with addition of water, and (c) with addition of deuterated water $\left(\mathrm{D}_{2} \mathrm{O}\right)$. bck denotes signals attributed to ions of the background. Circles identify the series $\mathrm{C}_{6} \mathrm{H}_{13}{ }^{+}\left(\mathrm{H}_{2} \mathrm{O}\right)_{n}(n=0,2-3)$ and rectangles the series $\mathrm{C}_{4} \mathrm{H}_{9}{ }^{+}\left(\mathrm{H}_{2} \mathrm{O}\right)_{n}$ $(n=0,3)$.

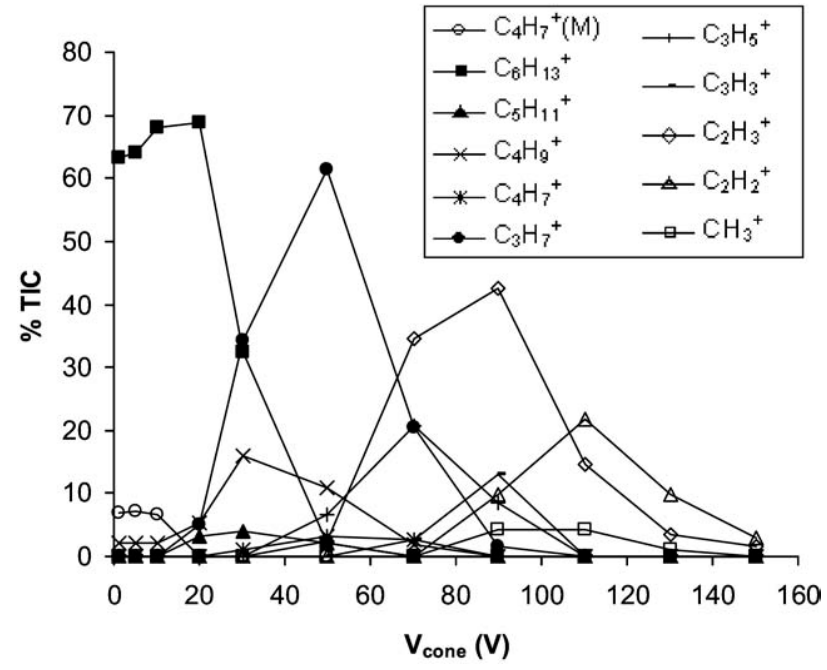

Figure 3. Energy resolved mass spectra of $n$-hexane at $30^{\circ} \mathrm{C}$ and $160 \mathrm{ppm}$.

tected at $30{ }^{\circ} \mathrm{C}$. In contrast, the complex $\mathrm{C}_{4} \mathrm{H}_{7}{ }^{+}(\mathrm{M})(\mathrm{m} / \mathrm{z}$ 141) is observed both at 30 and at $300{ }^{\circ} \mathrm{C}$.

As the concentration of $n$-hexane is increased, the relative intensities of $\mathrm{C}_{4} \mathrm{H}_{9}{ }^{+}$and $\mathrm{C}_{5} \mathrm{H}_{11}{ }^{+}$also increase, albeit slightly, with respect to that of $[\mathrm{M}-\mathrm{H}]^{+}$.

Experiments performed with addition of water into the source show the formation of hydrate clusters of $\mathrm{C}_{6} \mathrm{H}_{13}{ }^{+}(\mathrm{m} / \mathrm{z} 121,139)$ and $\mathrm{C}_{4} \mathrm{H}_{9}{ }^{+}(\mathrm{m} / \mathrm{z} 111)$, notably with two and three water molecules under the conditions used (Figure 2b). Addition of $\mathrm{D}_{2} \mathrm{O}$ confirmed these attributions by producing the expected mass shifts (Figure 2c). In contrast, the signal at $\mathrm{m} / \mathrm{z} 141$ does not shift, thus supporting the attribution to $\mathrm{C}_{4} \mathrm{H}_{7}{ }^{+}(\mathrm{M})$ rather than to the isobaric species $\mathrm{H}_{3} \mathrm{O}^{+}\left(\mathrm{H}_{2} \mathrm{O}\right)_{2} \mathrm{M}$ (Figure 2). Interestingly, the monohydrate complexes $\mathrm{C}_{6} \mathrm{H}_{13}{ }^{+}\left(\mathrm{H}_{2} \mathrm{O}\right)$ and $\mathrm{C}_{4} \mathrm{H}_{9}{ }^{+}\left(\mathrm{H}_{2} \mathrm{O}\right)$ were never observed at low $\mathrm{V}_{\text {cone }}$ even in the presence of very low levels of humidity but formed upon increasing $\mathrm{V}_{\text {cone }}$ as the products of CID of higher clusters. At increasing $\mathrm{V}_{\text {cone }}$ the fragmentation of $[\mathrm{M}-\mathrm{H}]^{+}$leads to $\mathrm{C}_{n} \mathrm{H}_{2 n+1}{ }^{+}$and $\mathrm{C}_{n} \mathrm{H}_{2 n-1}{ }^{+}$ions as shown in the energy-resolved mass spectra reported in the graph of Figure 3.

\section{Heptane Isomers}

n-Heptane. The signal attributed to $\mathrm{C}_{7} \mathrm{H}_{15}{ }^{+}$, i.e., $[\mathrm{M}-$ $\mathrm{H}^{+}(\mathrm{m} / z$ 99), is the base peak and also the only signal in the spectra of $n$-heptane recorded at $30^{\circ} \mathrm{C}$, low $\mathrm{V}_{\text {cone' }}$ and low hydrocarbon concentration, except for very minor signals attributed to $\mathrm{C}_{5} \mathrm{H}_{11}{ }^{+}(\mathrm{m} / z$ 71) and to the ion complex $\mathrm{C}_{4} \mathrm{H}_{7}{ }^{+}(\mathrm{M})(\mathrm{m} / \mathrm{z}$ 155) (Figure 4a). As already observed for $n$-hexane, the $n$-heptane complex $\mathrm{NO}^{+}(\mathrm{M})$ is detected only at high temperatures (Figure S3a in the Supplementary Material), whereas $\mathrm{C}_{4} \mathrm{H}_{7}{ }^{+}(\mathrm{M})$ is detected at both 30 and $300^{\circ} \mathrm{C}$. At higher $n$-heptane concentrations the intensities of the minor signals attributed to $\mathrm{C}_{5} \mathrm{H}_{11}{ }^{+}$and to ion complexes $\mathrm{C}_{4} \mathrm{H}_{7}{ }^{+}(\mathrm{M})$ and $\mathrm{NO}^{+}(\mathrm{M})$ grow with respect to that of $[\mathrm{M}-\mathrm{H}]^{+}$and 
(a)
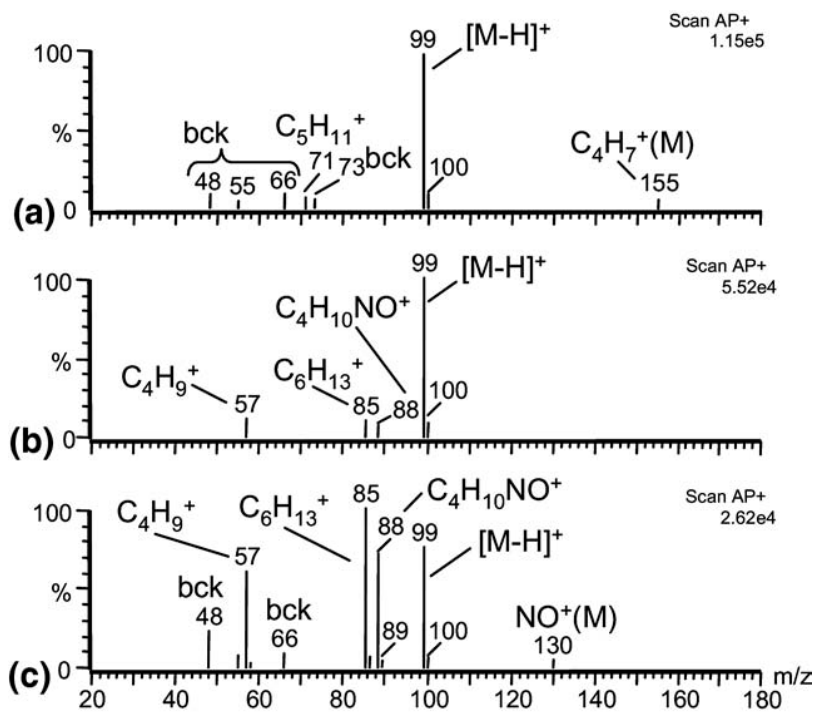

Figure 4. Positive APCI mass spectra at $30^{\circ} \mathrm{C}$ and $\mathrm{V}_{\text {cone }}=1 \mathrm{~V}$ of (a) n-heptane, (b) 2,4-dimethylpentane, and (c) 2,2-dimethylpentane.

new signals appear which are assigned to $\mathrm{C}_{4} \mathrm{H}_{9}{ }^{+}$and $\mathrm{C}_{6} \mathrm{H}_{13}{ }^{+}$(Figure S3b). As $\mathrm{V}_{\text {cone }}$ is increased, $[\mathrm{M}-\mathrm{H}]^{+}$ fragments via propene loss, leading to $\mathrm{C}_{4} \mathrm{H}_{9}{ }^{+}$(Figure S3c). At higher cone voltages, the products of greater energy fragmentation reactions are observed: $\mathrm{C}_{3} \mathrm{H}_{7}{ }^{+}, \mathrm{C}_{3} \mathrm{H}_{5}{ }^{+}$, $\mathrm{C}_{3} \mathrm{H}_{3}{ }^{+}, \mathrm{C}_{2} \mathrm{H}_{5}{ }^{+}, \mathrm{C}_{2} \mathrm{H}_{3}{ }^{+}$, and $\mathrm{CH}_{3}{ }^{+}$(Figure $\mathrm{S} 3 \mathrm{~d}$ ).

2,4-Dimethylpentane. The behavior of 2,4-dimethylpentane in air plasma is similar to that of its linear isomer $n$-heptane. Notably, at low cone voltages, the largely dominant species is $[\mathrm{M}-\mathrm{H}]^{+}(\mathrm{m} / \mathrm{z}$ 99) under any temperature and concentration tested (Figure 4b). Additional minor product ions observed at low hydrocarbon concentrations include $\mathrm{C}_{6} \mathrm{H}_{13}{ }^{+}\left(\mathrm{m} / z\right.$ 85), $\mathrm{C}_{4} \mathrm{H}_{9}{ }^{+}(\mathrm{m} / \mathrm{z}$ 57), and a species with $\mathrm{m} / \mathrm{z} 88$, which is attributed to $\mathrm{C}_{4} \mathrm{H}_{10} \mathrm{NO}^{+}$based on literature reports [22]. The relative abundance of the former two species appears to increase with temperature, whereas that of $\mathrm{C}_{4} \mathrm{H}_{10} \mathrm{NO}^{+}$is not significantly affected by temperature. As $\mathrm{V}_{\text {cone }}$ is increased, $[\mathrm{M}-\mathrm{H}]^{+}, \mathrm{C}_{6} \mathrm{H}_{13}{ }^{+}$, and $\mathrm{C}_{4} \mathrm{H}_{10} \mathrm{NO}^{+}$dissociate to $\mathrm{C}_{4} \mathrm{H}_{9}{ }^{+}$by propene, ethylene, and $\mathrm{HNO}$ loss, respectively. At yet higher $\mathrm{V}_{\text {cone, }}$ fragments $\mathrm{C}_{3} \mathrm{H}_{7}{ }^{+}, \mathrm{C}_{3} \mathrm{H}_{5}{ }^{+}$, $\mathrm{C}_{2} \mathrm{H}_{5}{ }^{+}$, and $\mathrm{C}_{2} \mathrm{H}_{3}{ }^{+}$are detected.

2,2-Dimethylpentane. In contrast with its isomers $n$ heptane and 2,4-dimethylheptane, 2,2-dimethylpentane gives $\mathrm{C}_{6} \mathrm{H}_{13}{ }^{+}$, i.e., $\left[\mathrm{M}-\mathrm{CH}_{3}\right]^{+}(\mathrm{m} / \mathrm{z} 85)$, as the most abundant ion within the air plasma under all conditions investigated (Figure 4c). Additional major products are $\left[\mathrm{M}-\mathrm{H}^{+}{ }^{+}\left(m / z\right.\right.$ 99) and $\mathrm{C}_{4} \mathrm{H}_{10} \mathrm{NO}^{+}(\mathrm{m} / \mathrm{z}$ 88). The concentration of the precursor hydrocarbon has opposite effects on the relative abundance of these two product ions: thus, as the concentration of $\mathrm{M}$ is increased $[\mathrm{M}-\mathrm{H}]^{+}$also increases, whereas $\mathrm{C}_{4} \mathrm{H}_{10} \mathrm{NO}^{+}$ decays probably via dissociation to $\mathrm{C}_{4} \mathrm{H}_{9}{ }^{+}$. This hypothesis is supported by the observation that the abundance of $\mathrm{C}_{4} \mathrm{H}_{9}{ }^{+}$increases with increasing hydrocarbon concentration.

As for ion/molecule complexes, the abundance of $\mathrm{NO}^{+}(\mathrm{M})(\mathrm{m} / \mathrm{z} 130)$ increases with increasing hydrocarbon concentration, whereas $\mathrm{C}_{4} \mathrm{H}_{7}{ }^{+}(\mathrm{M})(\mathrm{m} / \mathrm{z} 155)$ was not detected under any of the experimental conditions used. At increasing $\mathrm{V}_{\text {cone, }}$ fragmentation of $\mathrm{C}_{7} \mathrm{H}_{15}{ }^{+}$, $\mathrm{C}_{6} \mathrm{H}_{13}{ }^{+}$, and $\mathrm{C}_{4} \mathrm{H}_{10} \mathrm{NO}^{+}$leads to various products of $\mathrm{C}_{n} \mathrm{H}_{2 n+1}{ }^{+}$and $\mathrm{C}_{n} \mathrm{H}_{2 n-1}{ }^{+}$composition.

\section{Octane Isomers}

$n$-Octane. The positive APCI spectra of $n$-octane at $30{ }^{\circ} \mathrm{C}$ and low $\mathrm{V}_{\text {cone }}$ are characterized by the presence of both $\mathrm{M}^{+} \cdot(m / z 114)$ and $[\mathrm{M}-\mathrm{H}]^{+}(\mathrm{m} / z$ 113). As shown in Figure 5 , at $30^{\circ} \mathrm{C}$ the plasma ion population is strongly influenced by the hydrocarbon concentration. Specifically, the relative abundance of $\mathrm{M}^{+}$and $[\mathrm{M}-$ $\mathrm{H}]^{+}$changes significantly and the $[\mathrm{M}-\mathrm{H}]^{+} / \mathrm{M}^{+}$intensity ratio increases markedly with hydrocarbon concentration. In contrast, at $300{ }^{\circ} \mathrm{C}$ the $[\mathrm{M}-\mathrm{H}]^{+} / \mathrm{M}^{+}$. abundance ratio does not appear to change with hydrocarbon concentration and remains set at a value of about 5 .

(a)

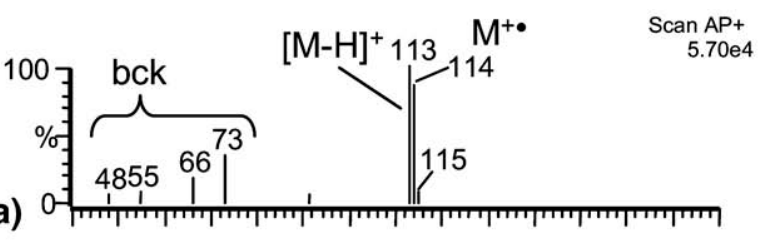

(b)

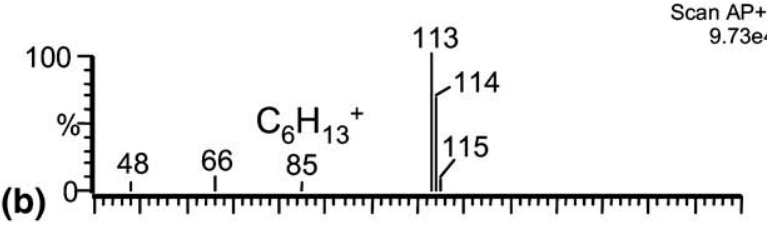

(c)

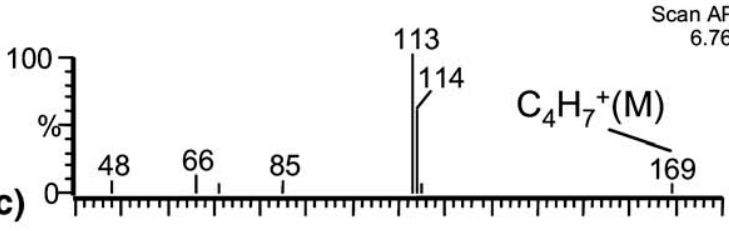

(d)

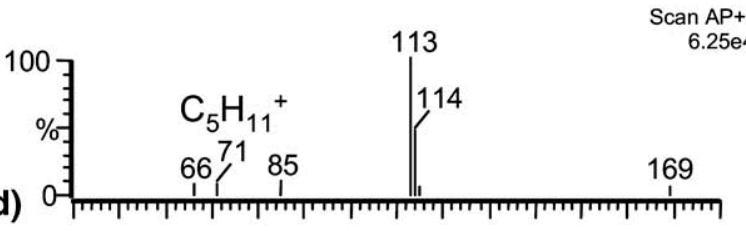

(e)

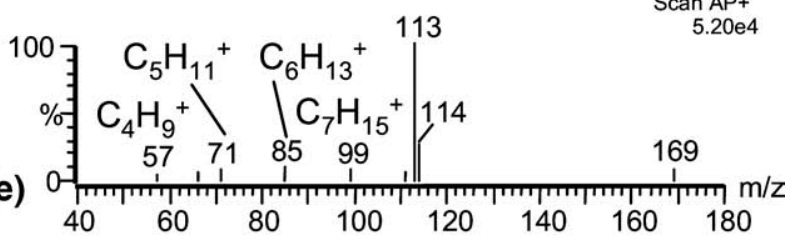

Figure 5. Positive APCI spectra of $n$-octane in synthetic air at $30{ }^{\circ} \mathrm{C}, \mathrm{V}_{\text {cone }}=1 \mathrm{~V}$ and at different $n$-octane concentrations of (a) 6 ppm, (b) 30 ppm, (c) 65 ppm, (d) 90 ppm, and (e) 150 ppm. 
As the hydrocarbon concentration is increased, $\mathrm{C}_{n} \mathrm{H}_{2 n+1}{ }^{+}$ions $(n=4-7)$ also begin to form at low $\mathrm{V}_{\text {cone }}$ values. Their abundance increases with hydrocarbon concentration (Figure 5), as already seen for the smaller linear hydrocarbons. As found with the other linear hydrocarbons, ion complexes $\mathrm{NO}^{+}(\mathrm{M})(\mathrm{m} / \mathrm{z} 144)$ and $\mathrm{C}_{4} \mathrm{H}_{7}{ }^{+}(\mathrm{M})(\mathrm{m} / z$ 169) are also observed, the former only

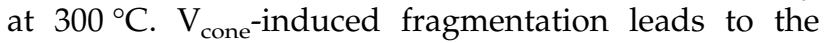
formation of $\mathrm{C}_{n} \mathrm{H}_{2 n+1}{ }^{+}(n=3-6)$ ions at low energies, and of $\mathrm{C}_{n} \mathrm{H}_{2 n+1}{ }^{+}(n=2)$ and $\mathrm{C}_{n} \mathrm{H}_{2,-1}{ }^{+}(n=2-3)$ ions at higher energies. At any given $\mathrm{V}_{\text {cone }}$ value applied, more extensive fragmentation is observed at 300 than at $30{ }^{\circ} \mathrm{C}$, an effect that can be ascribed to thermal decomposition of the ions, as described in the literature [17, 18, 28].

i-Octane (2,2,4-trimethylpentane). Similarly to 2,2dimethylpentane, the APCI mass spectrum of $i$-octane at low $\mathrm{V}_{\text {cone }}$ is also characterized by strong signals attributed to both $[\mathrm{M}-\mathrm{H}]^{+}(m / z 113)$ and $\left[\mathrm{M}-\mathrm{CH}_{3}\right]^{+}$ $(m / z$ 99) (Figure 6). Additional important signals are ascribed to $\mathrm{C}_{4} \mathrm{H}_{9}{ }^{+}(m / z 57), \mathrm{C}_{4} \mathrm{H}_{10} \mathrm{NO}^{+}(m / z$ 88), and $\mathrm{NO}^{+}(\mathrm{M})(m / z$ 144). The APCI mass spectrum is significantly influenced by the hydrocarbon concentration: Figure 6 shows that the abundance of $[\mathrm{M}-\mathrm{H}]^{+}(\mathrm{m} / \mathrm{z}$

(a)

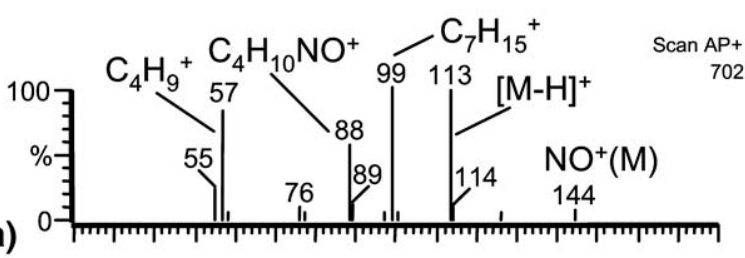

(b)

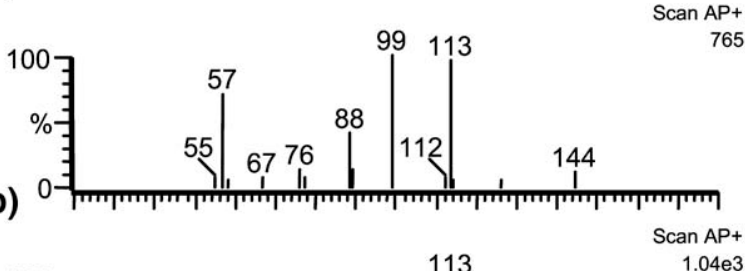

(c)

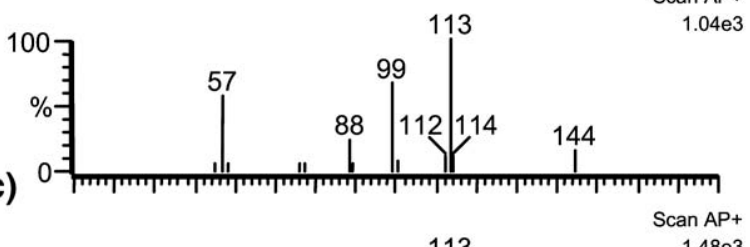

(d)
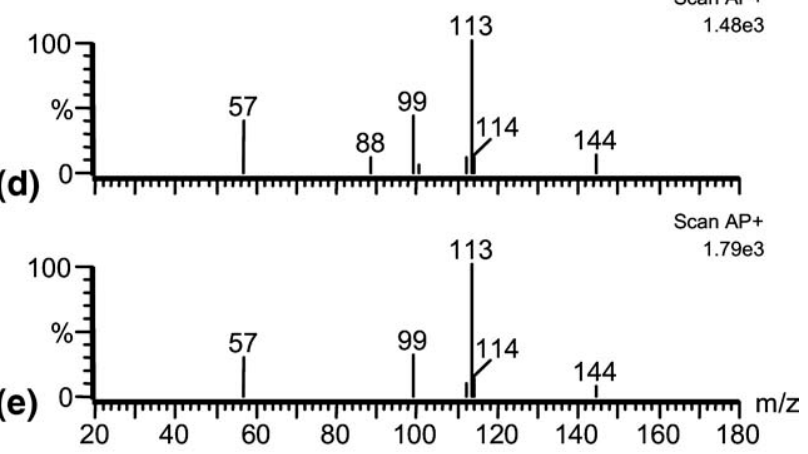

Figure 6. Positive APCI spectra of $i$-octane in synthetic air at $300{ }^{\circ} \mathrm{C}, \mathrm{V}_{\text {cone }}=1 \mathrm{~V}$ and at different $i$-octane concentrations of (a) 10 ppm, (b) 20 ppm, (c) 50 ppm, (d) 100 ppm, and (e) 200 ppm.
113) relative to that of $\mathrm{C}_{n} \mathrm{H}_{2 n+1}{ }^{+}(n<8)(m / z 57,99)$ ions increases with increasing $i$-octane concentration.

In contrast with the linear hydrocarbons, the complex $\mathrm{NO}^{+}(\mathrm{M})(\mathrm{m} / \mathrm{z} 144)$ is observed at both 300 and $30{ }^{\circ} \mathrm{C}$, whereas the species $\mathrm{C}_{4} \mathrm{H}_{7}{ }^{+}(\mathrm{M})(\mathrm{m} / \mathrm{z} 169)$ is not detected at any temperature within the range explored (Figure S4 in the Supplementary Material). $\mathrm{V}_{\text {cone-induced ion fragmentation is favored at higher }}$ temperatures: thus, although the same products $\left(\mathrm{C}_{4} \mathrm{H}_{9}{ }^{+}\right.$, $\mathrm{C}_{3} \mathrm{H}_{5}{ }^{+}, \mathrm{C}_{2} \mathrm{H}_{5}{ }^{+}$) are observed at 30 and at $300{ }^{\circ} \mathrm{C}$, they form at considerably lower $\mathrm{V}_{\text {cone }}$ values at 300 than at $30{ }^{\circ} \mathrm{C}$.

\section{Cyclohexane}

The APCI spectra of cyclohexane in air at low $\mathrm{V}_{\text {cone }}$ are dominated by the signal arising from $[\mathrm{M}-\mathrm{H}]^{+}(\mathrm{m} / \mathrm{z} 83)$ under any concentration and temperature conditions used (Figure S5a in the Supplementary Material). If the spectra at 30 and $300^{\circ} \mathrm{C}$ are compared, they differ only for the presence of the hydrate complexes: [M $\mathrm{H}^{+}\left(\mathrm{H}_{2} \mathrm{O}\right)_{n}(n=1,3 ; m / z 101,137)$ are observed only at $30{ }^{\circ} \mathrm{C}$ and $\mathrm{NO}^{+}(\mathrm{M})(\mathrm{m} / \mathrm{z} 114)$ only at $300{ }^{\circ} \mathrm{C}$. In contrast, the complex $\mathrm{C}_{4} \mathrm{H}_{7}{ }^{+}(\mathrm{M})(\mathrm{m} / z$ 139) is detected at both temperatures. The identity of the hydrate complexes was confirmed by experiments performed by adding water or deuterated water into the source. The expected changes in cluster intensity and distribution as well as, in the case of $\mathrm{D}_{2} \mathrm{O}$, the expected mass shifts were observed. No fragments of cyclohexane were ever detected in the spectra at low $\mathrm{V}_{\text {cone }}$ under any hydrocarbon concentration and temperature $\left(30-300{ }^{\circ} \mathrm{C}\right)$ tested. The fragmentation of $[\mathrm{M}-\mathrm{H}]^{+}$is observed only for $\mathrm{V}_{\text {cone }} \geq 70 \mathrm{~V}$ and leads mainly to $\mathrm{C}_{4} \mathrm{H}_{7}{ }^{+}$product ions. As observed in the case of $n$-octane and of the branched hydrocarbons, lower energy (lower $\mathrm{V}_{\text {cone }}$ ) is required to obtain the same fragmentation at 300 than at $30^{\circ} \mathrm{C}$ (Figure S5b in the Supplementary Material).

\section{Discussion}

A common feature of the APCI mass spectra in air of all investigated hydrocarbons $(\mathrm{M})$ is an intense signal attributed to $[\mathrm{M}-\mathrm{H}]^{+}$. This result is not surprising since $[\mathrm{M}-\mathrm{H}]^{+}$is the characteristic product in chemical ionization (CI) experiments of alkanes run with different reagent gases. For example, with methane as reagent gas, $[\mathrm{M}-\mathrm{H}]^{+}$is formed either via direct hydride abstraction by $\mathrm{C}_{2} \mathrm{H}_{5}{ }^{+}$or via protonation by $\mathrm{CH}_{5}{ }^{+}$and dissociation of $\mathrm{MH}^{+}$via $\mathrm{H}_{2}$ loss $[29,30]$. With nitric oxide as reagent gas, hydride transfer from the hydrocarbon to $\mathrm{NO}^{+}$is the main process observed [21]. Similarly, with dimethyl ether as reagent gas, $[\mathrm{M}-\mathrm{H}]^{+}$ is formed via hydride transfer to $\mathrm{C}_{2} \mathrm{H}_{5} \mathrm{O}^{+}$[31]. Atmospheric air plasmas are complex environments and several different ions are to be considered as potential reagent ions. Leaving aside the very short lived species $\mathrm{N}_{2}{ }^{+}, \mathrm{O}^{+}$, and $\mathrm{N}^{+}$, the major ones include $\mathrm{O}_{2}{ }^{+\bullet}, \mathrm{NO}^{+}$, and $\mathrm{H}_{3} \mathrm{O}^{+}$, both as bare species and/or as hydrates. 
Such ions have different reactivities and lifetimes: thus, whereas $\mathrm{H}_{3} \mathrm{O}^{+}, \mathrm{NO}^{+}$, and their hydrates form the "equilibrium" plasma ion population that is recorded in the APCI background spectra, $\mathrm{O}_{2}{ }^{+}$, a major primary ion formed by the discharge, and its hydrates are not observed because of reactions with water (eqs 1-3) [32-34], which are too fast for the time window of our experimental apparatus $(\sim 500 \mu \mathrm{s})[9,33]$.

$$
\begin{aligned}
& \mathrm{O}_{2}^{+\bullet}+\mathrm{H}_{2} \mathrm{O}\left(+\mathrm{N}_{2} \text { or } \mathrm{O}_{2}\right) \rightarrow \mathrm{O}_{2}^{+\bullet}\left(\mathrm{H}_{2} \mathrm{O}\right)\left(+\mathrm{N}_{2} \text { or } \mathrm{O}_{2}\right) \\
& \mathrm{O}_{2}^{+\bullet}\left(\mathrm{H}_{2} \mathrm{O}\right)+\mathrm{H}_{2} \mathrm{O} \rightarrow \mathrm{H}_{3} \mathrm{O}^{+}+\mathrm{O}_{2}+\mathrm{OH}^{\bullet} \\
& \rightarrow \mathrm{H}_{3} \mathrm{O}^{+} \cdot \mathrm{OH}^{\bullet}+\mathrm{O}_{2} \\
& \mathrm{H}_{3} \mathrm{O}^{+} \cdot \mathrm{OH}^{\bullet}+\mathrm{H}_{2} \mathrm{O} \rightarrow \mathrm{H}_{3} \mathrm{O}^{+}\left(\mathrm{H}_{2} \mathrm{O}\right)+\mathrm{OH}^{\bullet}
\end{aligned}
$$

Notoriously, these reactions also occur in "dry" air plasma because of the presence of trace amounts of residual humidity $[9,32,33,35]$.

In atmospheric air plasmas, therefore, hydrocarbon molecules can undergo competing reactions with different reagent ions. In turn, the formation of the reagent ions can be affected by the presence of the hydrocarbon. Specifically, the production of $\mathrm{H}_{3} \mathrm{O}^{+}\left(\mathrm{H}_{2} \mathrm{O}\right)_{n}$ from reactions $1-3$ can be inhibited by competing thermodynamically favorable reactions of the hydrocarbon with $\mathrm{O}_{2}{ }^{+\bullet}\left(\mathrm{H}_{2} \mathrm{O}\right)_{n}(n=0,1)$. Obviously, such oxygen ions can be important reagent ions in hydrocarbon plasma ion chemistry despite the fact that they are never detected in our background APCI spectra [36].

Based on the experimental results obtained in this study and on available literature data, a general scheme is proposed to account for the formation of $[\mathrm{M}-\mathrm{H}]^{+}$ within the atmospheric plasma generated by corona discharges in air containing a hydrocarbon M (Scheme 2). It comprises direct hydride abstraction reactions, notably by $\mathrm{NO}^{+}$(b) and by alkyl fragment ions $\mathrm{R}^{+}(\mathbf{d})$ as well as alternative processes, including charge exchange with $\mathrm{O}_{2}{ }^{+}$followed by $\mathrm{H}$-transfer to oxygen (a) and protonation by $\mathrm{H}_{3} \mathrm{O}^{+}$followed by $\mathrm{H}_{2}$ elimination (c). The scheme also shows how alkyl fragment ions $\mathrm{R}^{+}$

(a)

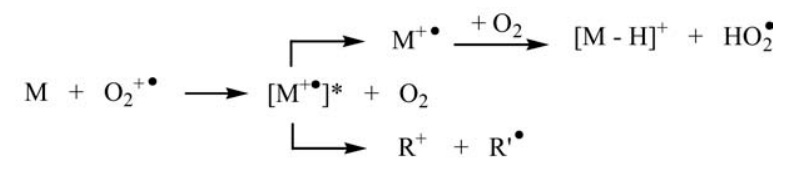

(b) $\mathrm{M}+\mathrm{NO}^{+} \longrightarrow[\mathrm{M}-\mathrm{H}]^{+}+\mathrm{HNO}$

(c) $\mathrm{M}+\mathrm{H}_{3} \mathrm{O}^{+} \longrightarrow[\mathrm{M}-\mathrm{H}]^{+}+\mathrm{H}_{2} \mathrm{O}+\mathrm{H}_{2}$

$$
\longrightarrow \mathrm{R}^{+}+\mathrm{R}^{\prime} \mathrm{H}+\mathrm{H}_{2} \mathrm{O}
$$

(d) $\mathrm{M}+\mathrm{R}^{+} \longrightarrow[\mathrm{M}-\mathrm{H}]^{+}+\mathrm{RH}$

Scheme 2. Possible routes for the formation of $[\mathrm{M}-\mathrm{H}]^{+}$and $\mathrm{R}^{+}$ in atmospheric air plasma. form from $\mathrm{M}$ as a consequence of ion/molecule reactions with $\mathrm{O}_{2}^{+\cdot}(\mathbf{a}), \mathrm{NO}^{+}(\mathbf{b})$, and $\mathrm{H}_{3} \mathrm{O}^{+}(\mathbf{c})$.

All reactions proposed in Scheme 2 have precedents in the literature. With regard to process (a), it is known that the main reaction of $\mathrm{O}_{2}^{+}$with alkanes is charge transfer, which occurs at collision rate, and, depending on the hydrocarbon, can be nondissociative and/or dissociative [17-19]. Specifically, charge transfer from $\mathrm{O}_{2}{ }^{+}$to $\mathrm{M}$ is energetically highly favorable for all hydrocarbons considered in this study $(\Delta \mathrm{H}$ of reaction ranges from -172.7 to $-219.0 \mathrm{~kJ} \mathrm{~mol}^{-1}$ for linear $C_{5}$ to $\mathrm{C}_{8}$ hydrocarbons [37]) and is therefore a most likely route for the formation of alkyl fragment ions $\left(\mathrm{R}^{+}\right)$. Only for $n$-octane, among all hydrocarbons analyzed in this study, is such charge transfer not completely dissociative and the molecular ion, $\mathrm{M}^{+}$, is detected in the APCI spectra. This finding is consistent with the observation that in the reaction of linear hydrocarbons with $\mathrm{O}_{2}{ }^{+}$, longer carbon chains increase the stability of $\mathrm{M}^{+} \cdot$ with regard to both hydrogen transfer to $\mathrm{O}_{2}$ [17] and fragmentation to alkyl cations [19]. As for the formation of $[\mathrm{M}-\mathrm{H}]^{+}$, it was found that the two-step process shown in (a) is kinetically favored with respect to direct hydride transfer from $\mathrm{M}$ to $\mathrm{O}_{2}{ }^{+}$[17].

As for process (b), SIFT (selected ion flow tube) experiments $[18,19,22]$ have shown that hydride abstraction by $\mathrm{NO}^{+}$is exothermic for all hydrocarbons analyzed in the present study. Moreover, for $n$-pentane, $n$-octane, and $i$-octane, the formation of alkyl fragments was also reported although, at $300 \mathrm{~K}$, it accounted for only $<10 \%$ of the observed $[\mathrm{M}-\mathrm{H}]^{+}$[22].

Protonation by $\mathrm{H}_{3} \mathrm{O}^{+}$followed by $\mathrm{H}_{2}$ loss (process c), was observed as a minor reaction channel in a SIFT study of several alkanes including $n$-hexane, $n$-heptane, $n$-octane, and $i$-octane [22]: this reaction was indeed estimated to be endothermic for $n$-hexane, $n$-heptane, and n-octane, thus accounting for its low efficiency. Notably, fragment alkyl cations $\mathrm{C}_{n} \mathrm{H}_{2 n+1}{ }^{+}$were also observed as minor products in these reactions [22]. Finally, the reactions of alkyl fragments $\mathrm{R}^{+}$with alkanes have been extensively studied by means of different experimental techniques. When exothermic or approximately thermoneutral, hydride transfer (process d) is generally the major reaction pathway observed [20, 38-41]. In our APCI experiments at low energies (low $\mathrm{V}_{\text {cone }}$ values), very weak signals are observed for fragment ions $\mathrm{C}_{n} \mathrm{H}_{2 n+1}{ }^{+}$in the case of linear hydrocarbons, whereas comparatively larger amounts are obtained from the branched hydrocarbons because of the higher stability of tertiary alkyl fragment ions. No ionic fragments are observed in the case of cyclohexane at low $\mathrm{V}_{\text {cone }}$ values.

Indirect evidence for the occurrence of process (d) in our system comes from experiments in which the effect of the hydrocarbon concentration was studied, notably with the octanes. Thus, in the case of $i$-octane, from which abundant $\mathrm{R}^{+}$are produced, it is found that as the concentration of $M$ is increased that of fragments $R^{+}$ decreases relative to $[\mathrm{M}-\mathrm{H}]^{+}$(Figure 6). This obser- 
vation suggests that hydride abstraction from $\mathrm{R}^{+}$might be an important route for $[\mathrm{M}-\mathrm{H}]^{+}$formation within atmospheric air plasmas. Specifically, hydride abstraction from $i$-octane is estimated to be exothermic for the major fragments observed, i.e., $\mathrm{C}_{7} \mathrm{H}_{15}{ }^{+}\left(\Delta \mathrm{H}_{\mathrm{r}}=-39.9 \mathrm{~kJ}\right.$ $\left.\mathrm{mol}^{-1}[22,37]\right)$ and $t-\mathrm{C}_{4} \mathrm{H}_{9}{ }^{+}\left(\Delta \mathrm{H}_{\mathrm{r}}=-62.1 \mathrm{~kJ} \mathrm{~mol}^{-1}[22\right.$, 37, 42]).

In the case of $n$-octane, for which both $\mathrm{M}^{+}$and [M $\mathrm{H}^{+}$are observed, we found that upon increasing the concentration of $\mathrm{M}$ the abundance of $\mathrm{M}^{+}$decreases relative to that of $[\mathrm{M}-\mathrm{H}]^{+}$(Figure 5). Since fragmentation of $\mathrm{M}^{+\bullet}$ to $[\mathrm{M}-\mathrm{H}]^{+}$via $\mathrm{H}^{\bullet}$ loss is highly unlikely, this outcome is to be ascribed to ion/molecule reactions involving $\mathrm{M}$ as neutral reactant and $[\mathrm{M}-\mathrm{H}]^{+}$ as product. The reactant ions are most likely ionic fragments, which become more abundant as the concentration of $\mathrm{M}$ is increased, thus favoring reaction (d) of Scheme 2 [38].

As the ions kinetic energy is increased, CID is observed (Figures 1 and 3). The energy-resolved spectral data of Figure 3 are consistent with known ion dissociation pathways. Thus, we find that upon increasing the ion energy the hexyl cation, which is the most abundant ion at low energies, decays and two new ions appear, $\mathrm{C}_{3} \mathrm{H}_{7}{ }^{+}$and $\mathrm{C}_{4} \mathrm{H}_{9}{ }^{+}$. These are known dissociation products of $\mathrm{C}_{6} \mathrm{H}_{13}{ }^{+}$formed via alkene elimination, propene, and ethane, respectively [30]. A minor contribution to the same ionic products is probably attributable to the dissociation of $\left(\mathrm{C}_{4} \mathrm{H}_{7}{ }^{+}\right) \mathrm{M}$ as discussed in the following text. At higher energies the propyl cation dissociates to $\mathrm{C}_{3} \mathrm{H}_{5}{ }^{+}, \mathrm{C}_{2} \mathrm{H}_{3}{ }^{+}$, and $\mathrm{C}_{2} \mathrm{H}_{2}{ }^{+}$, the characteristic fragments observed in electron ionization of propane.

In addition to $[\mathrm{M}-\mathrm{H}]^{+}$and $\mathrm{C}_{n} \mathrm{H}_{2 n+1}{ }^{+}$ions, all branched alkanes considered in this work also form an interesting product ion of $\mathrm{C}_{4} \mathrm{H}_{10} \mathrm{NO}^{+}$composition. The relative abundance of this product ion is quite significant in the case of $i$-octane and 2,2-dimethylpentane, whereas it reaches at most a value of $10 \%$ in the case of 2,4-dimethylpentane. No such or related product ions were observed in our experiments with $n$-alkanes. Interestingly, Arnold et al. reported this $\mathrm{C}_{4} \mathrm{H}_{10} \mathrm{NO}^{+}$ species as one of the products of the reaction of $\mathrm{NO}^{+}$ with $n$-heptane [22] and n-octane [18]. Homologues $\mathrm{C}_{n} \mathrm{H}_{2 n+2} \mathrm{NO}^{+}$with $n=2,3$, and 5 were also detected and were all assigned the structure of protonated nitrosoalkanes, $\mathrm{C}_{n} \mathrm{H}_{2 n+1} \mathrm{NOH}^{+}$[22]. In contrast, none of these product ions formed in the reaction of $\mathrm{NO}^{+}$with $i$-octane [18]. Spanel and Smith also found $\mathrm{C}_{n} \mathrm{H}_{2 n+2} \mathrm{NO}^{+}$ as minor products of the reaction of $\mathrm{NO}^{+}$with $n$ alkanes of chain longer than 6 carbons [19]. Thus, the $n$-dodecane reaction produced 6 such $\mathrm{C}_{n} \mathrm{H}_{2 n+2} \mathrm{NO}^{+}$ ions with $n=3-8$. The structure of protonated formamide derivatives $\left(\mathrm{HCONHC}_{n-1} \mathrm{H}_{2 n}\right) \mathrm{H}^{+}$was suggested for these unusual products, but no mechanistic suggestions were given for the extensive molecular rearrangement required to attain the proposed structure [19].

We suggest that in atmospheric air plasma $\mathrm{C}_{4} \mathrm{H}_{10} \mathrm{NO}^{+}$ forms from a hydrocarbon- $\mathrm{NO}^{+}$complex via (i) hydride abstraction by $\mathrm{NO}^{+}$and (ii) olefin elimination as shown in Scheme 3 for $i$-octane $\left(\mathrm{R}=\mathrm{CH}_{3}\right)$ and 2,2dimethylpentane $(\mathrm{R}=\mathrm{H})$. The proposed ion/molecule structure, i.e., $t-\mathrm{C}_{4} \mathrm{H}_{9}{ }^{+}(\mathrm{HNO})$, for the $\mathrm{C}_{4} \mathrm{H}_{10} \mathrm{NO}^{+}$product ion is consistent with the observation that at high $\mathrm{V}_{\text {cone }}$ such species dissociates to $\mathrm{C}_{4} \mathrm{H}_{9}{ }^{+}$via $\mathrm{HNO}$ loss (Scheme 3). The scheme also comprises steps leading to other observed products: the ion/neutral complex $\mathrm{NO}^{+}(\mathrm{M})$ and $[\mathrm{M}-\mathrm{H}]^{+}$. It is reasonably expected that olefin elimination is viable only when a stable carbenium ion can be formed. Thus, reaction with 2,4dimethylpentane also produces $\mathrm{C}_{4} \mathrm{H}_{10} \mathrm{NO}^{+}$, rather than the direct cleavage product $\mathrm{C}_{3} \mathrm{H}_{8} \mathrm{NO}^{+}$, the 2propyl cation/HNO complex. An additional proton transfer step (exothermic by $202.8 \mathrm{~kJ} \mathrm{~mol}^{-1}[37,42]$ ) is required in this case to form the $\mathrm{C}_{4} \mathrm{H}_{10} \mathrm{NO}^{+}$product ion (Scheme 4).

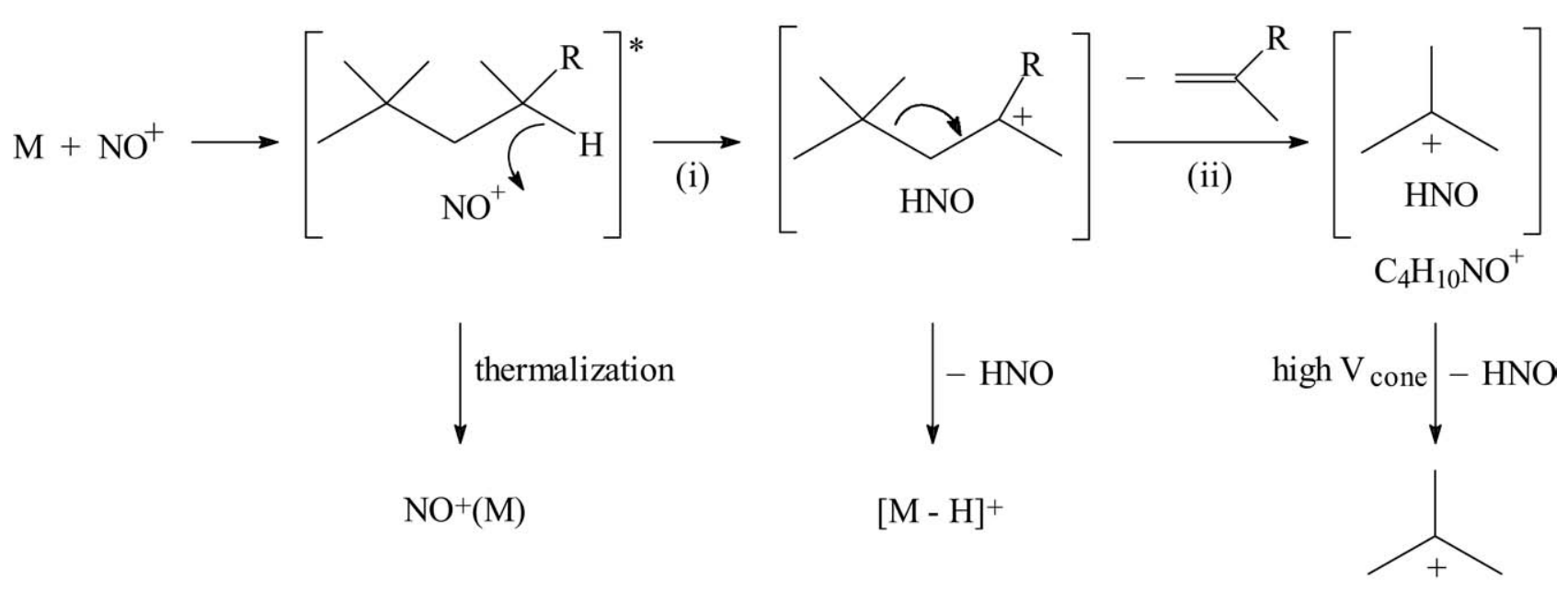

Scheme 3. Reactions of $i$-octane $\left(\mathrm{R}=\mathrm{CH}_{3}\right)$ and 2,2-dimethylpentane $(\mathrm{R}=\mathrm{H})$ with $\mathrm{NO}^{+}$in atmospheric air plasma. 


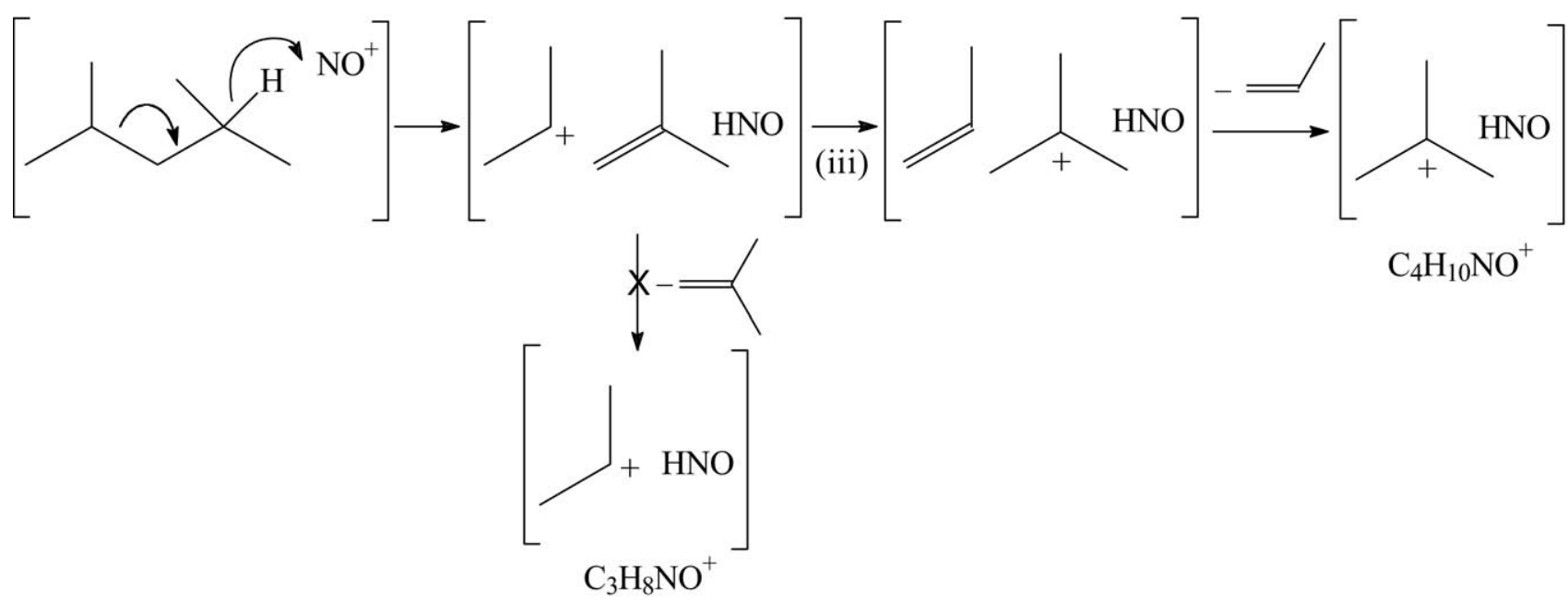

Scheme 4. Formation of $\mathrm{C}_{4} \mathrm{H}_{10} \mathrm{NO}^{+}$from 2,4-dimethylpentane in atmospheric air plasma.

Analogous $\mathrm{C}_{n} \mathrm{H}_{2 n+2} \mathrm{NO}^{+}$products with $n<4$ were never detected in our experiments, consistent with the suggestion that the reaction is driven by the stability of the cation formed in the olefin-elimination step.

As for the association reaction to form $\mathrm{NO}^{+}(\mathrm{M})$, we found no temperature dependence in the case of branched hydrocarbons, whereas, in the case of linear hydrocarbons and cyclohexane, $\mathrm{NO}^{+}(\mathrm{M})$ was observed only at $300{ }^{\circ} \mathrm{C}$. This is quite strange because, generally, the formation of complexes is favored by low temperatures, higher temperatures leading to their dissociation. However, considering that in APCI experiments at $30{ }^{\circ} \mathrm{C} \mathrm{NO}^{+}$is generally observed as the hydrated species, $\mathrm{NO}^{+}\left(\mathrm{H}_{2} \mathrm{O}\right)$, probably ligand switching to form $\mathrm{NO}^{+}(\mathrm{M})$ via water displacement by $\mathrm{M}$ (eq 4) is not favored at this temperature.

$$
\mathrm{NO}^{+}\left(\mathrm{H}_{2} \mathrm{O}\right)+\mathrm{M} \rightarrow \mathrm{NO}^{+}(\mathrm{M})+\mathrm{H}_{2} \mathrm{O}
$$

Thermodynamic data on complexes between $\mathrm{NO}^{+}$and the alkanes considered in the present study are not available, although calculations predict that reaction 4 should have a positive $\Delta \mathrm{G}$ of $+51.9 \mathrm{~kJ} \mathrm{~mol}^{-1}$ in the case $\mathrm{M}=\mathrm{CH}_{4}[43,44]$. In contrast, the three-body associa- tion that leads to the formation of the complex $\mathrm{NO}^{+}(\mathrm{M})$ [45] is favored at $300{ }^{\circ} \mathrm{C}$.

Another peculiar ion observed in the atmospheric air plasma mass spectra of all linear alkanes investigated is a species of composition corresponding to $\mathrm{C}_{4} \mathrm{H}_{7}{ }^{+}(\mathrm{M})$. We believe this species might derive from addition of $[\mathrm{M}-\mathrm{H}]^{+}$to a $\mathrm{C}_{4} \mathrm{H}_{8}$ olefin to form a new carbenium ion as shown in Scheme 5 for $n$-hexane.

Addition of alkyl ions to olefins in the gas phase has been described in chemical ionization studies, but usually the adduct is not detected because it undergoes fragmentation as a result of the reaction exothermicity [46]. Adducts of the type proposed in Scheme 5 have been observed in APCI experiments on various alkenes [47].

It is expected that, as the energy is increased, this addition product should undergo direct olefin elimination to $[\mathrm{M}-\mathrm{H}]^{+}$or rearrangement followed by olefin elimination to form different $\mathrm{C}_{n} \mathrm{H}_{2 n+1}{ }^{+}$fragment ions as sketched in Scheme 5. The energy-resolved mass spectrum of $n$-hexane (Figure 3 ) is consistent with this hypothesis, showing that upon increasing energy, the relative abundance of the addition product $\mathrm{C}_{10} \mathrm{H}_{21}{ }^{+}$ decreases, whereas those of fragment ions $\mathrm{C}_{6} \mathrm{H}_{13}{ }^{+}$,

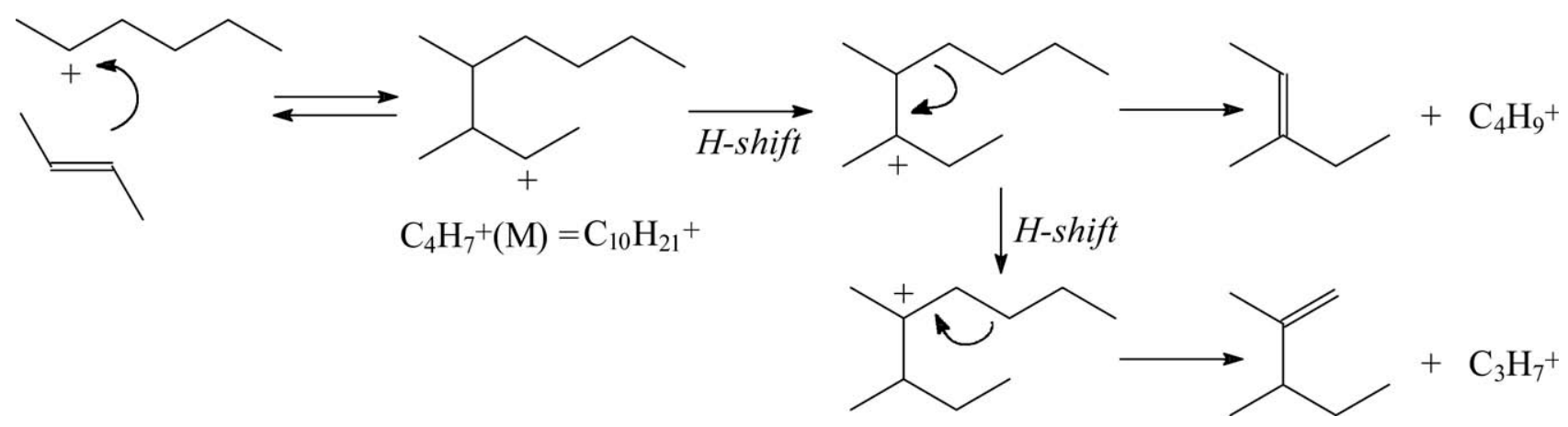

Scheme 5. Formation of $\mathrm{C}_{10} \mathrm{H}_{21}{ }^{+}$from $n$-hexane and its dissociation in atmospheric air plasma. 
$\mathrm{C}_{4} \mathrm{H}_{9}{ }^{+}$, and $\mathrm{C}_{3} \mathrm{H}_{7}{ }^{+}$increase correspondingly. Analogous addition products are not seen with branched alkanes probably because, as the result of branching, such products have a greater tendency to fragment.

A comment is also appropriate with respect to the effect of temperature on ion fragmentation. It is found that, upon increasing $\mathrm{V}_{\text {cone, }}$ more advanced fragmentation is observed at 300 than at $30^{\circ} \mathrm{C}$. This is true for $n$-octane and for all branched alkanes and is consistent with literature data, which report that thermal decomposition affects the relative fractions of dissociated and nondissociated ions [17, 18, 28].

Finally, the formation of the ion $[\mathrm{M}-3 \mathrm{H}]^{+}$, observed in the case of linear alkanes, can be ascribed to the reaction of $\mathrm{M}$ with $\mathrm{NO}^{+}$. In fact Hunt and Harvey observed this product in chemical ionization of saturated hydrocarbons with $\mathrm{NO}^{+}$[21]. To explain its origin, they postulated the formation of a long-lived three-body collision complex comprising $\mathrm{NO}^{+}$, the alkane, and a neutral nitric oxide molecule. Within such a complex the ion $[\mathrm{M}-3 \mathrm{H}]^{+}$is formed via multiple hydrogen transfers along with neutral products $\mathrm{HN}=\mathrm{OH}$ and $\mathrm{HNO}$ [21].

\section{Conclusions}

The results of APCI analysis of highly diluted alkanes in air disclose a rich ion chemistry that is characterized by the formation of $[\mathrm{M}-\mathrm{H}]^{+}$both for linear and branched hydrocarbons and for cyclohexane. Such $[\mathrm{M}-\mathrm{H}]^{+}$ product ions arise from the reaction of $\mathrm{M}$ with air plasma ions, notably $\mathrm{O}_{2}{ }^{+}, \mathrm{NO}^{+}, \mathrm{H}_{3} \mathrm{O}^{+}$, and their hydrates; alkyl fragment ions also form in these reactions and in turn contribute to the formation of [M $\mathrm{H}^{+}$. The reaction with $\mathrm{NO}^{+}$includes complex formation and hydride abstraction accompanied, in the case of the branched alkanes, by olefin elimination. Finally, our experiments have revealed interesting higher alkyl ion products that are likely attributable to addition of $[\mathrm{M}-\mathrm{H}]^{+}$to olefins.

\section{References}

1. Tendero, C.; Tixier, C.; Tristant, P.; Desmaison, J.; Leprince, P. Atmospheric Pressure Plasmas: A Review. Spectrochim. Acta B Atom. Spectrosc. 2006, 61, 230.

2. Electrical Discharges for Environmental Purposes: Fundamentals and Applications; van Veldhuizen, E. M., Ed.; Huntington/Nova Science Publishers, Inc.: New York, 2000.

3. Kim, H.-H. Nonthermal Plasma Processing for Air-Pollution Control: A Historical Review, Current Issues, and Future Prospects. Plasma Process. Polym. 2004, 1, 91-110.

4. See for example: (a)Brisset, J.-L.; Moussa, D.; Doubla, A.; Hnatiuc, E.; Hnatiuc, B.; Youbi, G. K.; Herry, J.-M.; Naïtali, M.; Bellon-Fontaine, M.-N. Chemical Reactivity of Discharges and Temporal Post-Discharges in Plasma Treatment of Aqueous Media: Examples of Gliding Discharge Treated Solutions. Ind. Eng. Chem. Res. 2008, 47, 5761-5781; (b) Locke, B. R.; Sano, M.; Sunka, P.; Hoffmann, M. R.; Chang, J. S. Electrohydraulic Discharge and Nonthermal Plasma for Water Treatment. Ind. Eng. Chem. Res. 2006, 45, 882-905; (c) Grabowski, L. R.; van Veldhuizen, E. M.; Pemen, A. J. M.; Rutgers, W. R. Corona above Water Reactor for Systematic Study of Aqueous Phenol Degradation. Plasma Chem. Plasma Process. 2006, 26, 3-17.

5. Kim, H.-H.; Kobara, H.; Ogata, A.; Futamura, S. Comparative Assessment of Different Nonthermal Plasma Reactors on Energy Efficiency and Aerosol Formation from the Decomposition of Gas-Phase Benzene. IEEE Trans. Ind. Appl. 2005, 41, 206-214.
6. Atkinson, R. Gas-Phase Degradation of Organic Compounds in the Troposphere. Pure Appl. Chem. 1998, 70, 1327-1334.

7. Penetrante, B. M.; Hsiao, M. C.; Bardsley, J. N.; Merritt, B. T.; Vogtlin, G. E.; Wallmann, P. H. Electron Beam and Pulsed Corona Processing of Volatile Organic Compounds in Gas Streams. Pure Appl. Chem. 1996, 68, 1083-1087.

8. Krasnoperov, L. N.; Krishtopa, L. G.; Bozzelli, J. W. Study of Volatile Organic Compounds Destruction by Dielectric Barrier Corona Discharge. J. Adv. Oxidat. Technol. 1997, 2, 248-256.

9. Donò, A.; Paradisi, C.; Scorrano, G. Abatement of VOCs by Corona Discharge. A Study of the Reactivity of Trichloroethylene under Atmospheric Pressure Ionization Conditions. Rapid Commun. Mass Spectrom. 1997, 11, 1687-1694.

10. Sieck, L. W.; Buckley, T. J.; Herron, J. T.; Green, D. S. Pulsed Electron Beam Ionization of Humid Air and Humid Air/Toluene Mixtures: Time-Resolved Cationic Kinetics and Comparison with Predictive Models. Plasma Chem. Plasma Process. 2001, 21, 441-457.

11. Rudolph, R.; Francke, K.-P.; Miessner, H. Concentration Dependence of VOC Decomposition by Dielectric Barrier Discharges. Plasma Chem. Plasma Process. 2002, 22, 401-412.

12. Marotta, E.; Scorrano, G.; Paradisi, C. Ionic Reactions of Chlorinated VOCs in Air Plasma at Atmospheric Pressure. Plasma Process. Polym. 2005, 2, 209-217.

13. (a) Marotta, E.; Paradisi, C.; Scorrano, G. An Atmospheric Pressure Chemical Ionization Study of the Positive and Negative Ion Chemistry of Hydrofluorocarbons 1,1-Ddifluoroethane (HFC-152a) and 1,1,1,2Tetrafluoroethane (HFC-134a) and of Perfluoro- $n$-hexane (FC-72) in Air Plasma at Atmospheric Pressure. J. Mass Spectrom. 2004, 39, 791-801; (b) Marotta, E.; Cooks, R. G.; Paradisi, C. Novel CFCs-Substitutes Recommended by EPA (Hydrofluorocarbon-245fa and Hydrofluoroether-7100): Ion Chemistry in Air Plasma and Reactions with Atmospheric Ions. J. Am. Soc. Mass Spectrom. 2005, 16, 1081-1092; (c) Marotta, E.; Paradisi, C. Positive Ion Chemistry of Esters of Carboxylic Acids in Air Plasma at Atmospheric Pressure. J. Mass. Spectrom. 2005, 40, 1583-1589.

14. Marotta, E.; Callea, A.; Rea, M.; Paradisi, C. DC Corona Electric Discharges for Air Pollution Control. 1. Efficiency and Products of Hydrocarbon Processing. Environ. Sci. Technol. 2007, 41, 5862-5868.

15. Marotta, E.; Callea, A.; Ren, X.; Rea, M.; Paradisi, C. A Mechanistic Study of Pulsed Corona Processing of Hydrocarbons in Air at Ambient Temperature and Pressure. Int. J. Plasma Environ. Sci. Technol. 2007, 1, 39-45.

16. Marotta, E.; Callea, A.; Ren, X.; Rea, M.; Paradisi, C. DC Corona Electric Discharges for Air Pollution Control. 2. Ionic Intermediates and Mechanisms of Hydrocarbon Processing. Plasma Process. Polym. 2008, 5 , $146-154$.

17. Matsuoka, S.; Ikezoe, Y. Ion-Molecule Reactions and Thermal Decomposition of Ions in $\mathrm{N}_{2}-\mathrm{O}_{2}$-alkane $\left(\mathrm{C}_{2}-\mathrm{C}_{8}\right)$ Mixtures Studied by TimeResolved Atmospheric Pressure Ionization Mass Spectrometry. J. Phys. Chem. 1988, 92, 1126-1133.

18. Arnold, S. T.; Viggiano, A. A.; Morris, R. A. Rate Constants and Branching Ratios for the Reactions of Selected Atmospheric Primary Cations with $n$-Octane and Isooctane (2,2,4-Trimethylpentane). J. Phys. Chem. A 1997, 101, 9351-9358.

19. Spanel, P.; Smith, D. Selected Ion Flow Tube Studies of the Reactions of $\mathrm{H}_{3} \mathrm{O}^{+}, \mathrm{NO}^{+}$and $\mathrm{O}_{2}{ }^{+}$with Several Aromatic and Aliphatic Hydrocarbons. Int. J. Mass. Spectrom. 1998, 181, 1-10.

20. Searles S. K.; Sieck, L. W. High Pressure Photoionization Mass Spectrometry. III. Reactions of $\mathrm{NO}^{+}\left(\mathrm{X \Sigma}^{2} 1^{+}\right)$with $\mathrm{C}_{3}-\mathrm{C}_{7}$ Hhydrocarbons at Thermal Kinetic Energies. J. Chem. Phys. 1970, 53, 794-798.

21. Hunt, D. F.; Harvey, T. M. Nitric Oxide Chemical Ionization Mass Spectra of Alkanes. Anal. Chem. 1975, 47, 1965-1969.

22. Arnold, S. T.; Viggiano, A. A.; Morris, R. A. Rate Constants and Branching Fractions for the Reactions of $\mathrm{H}_{3} \mathrm{O}^{+}$and $\mathrm{NO}^{+}$with $\mathrm{C}_{2}-\mathrm{C}_{12}$ Alkanes. J. Phys. Chem. A 1998, 102, 8881-8887.

23. Bell, S. E.; Ewing, R. G.; Eiceman, G. A.; Karpas, Z. Atmospheric Pressure Chemical Ionization of Alkanes, Alkenes, and Cycloalkanes. J. Am. Soc. Mass Spectrom. 1994, 5, 177-185.

24. Borsdorf, H.; Schelhorn, H.; Flachowsky, J.; Döring, H.-R.; Stach, J. Corona Discharge Ion Mobility Spectrometry of Aliphatic and Aromatic Hydrocarbons. Anal. Chim. Acta 2000, 403, 235-242.

25. Matveev, I. B.; Rosocha, L. A., Guest Editors. Special Issue on PlasmaAssisted Combustion. IEEE Trans. Plasma Sci. 2006, 34

26. Rosocha, L. A.; Kim, Y.; Anderson, G. K.; Lee, J. O.; Abbate, S. Decomposititon of Ethane in Atmospheric-Pressure Dielectric Barrier Discharges: Experiments. IEEE Trans. Plasma Sci. 2006, 34, 2526-2531.

27. Kim, Y.; Ferreri, V. W.; Rosocha, L. A.; Anderson, G. K.; Abbate, S.; Kim K.-T. Effect of Plasma Chemistry on Activated Propane-Air Flames. IEEE Trans. Plasma Sci. 2006, 34, 2532-2536.

28. Meot-Ner, M.; Field, F. H. Unimolecular Thermal Decomposition Reactions of Gaseous Carbonium Ions. J. Phys. Chem. 1976, 80, 2865-2869.

29. (a) Field, F. H.; Munson, M. S. B.; Becker, D. A. Chemical Ionization Mass Spectrometry. Paraffin Hydrocarbons. Adv. Chem. Ser. 1966, 58, 167-192; (b) Field, F. H.; Munson, M. S. B. Chemical Ionization Mass Spectrometry. V. Cycloparaffins. J. Am. Chem. Soc. 1967, 89, 4272-4280; (c) Field, F. H. Chemical Ionization Mass Spectrometry. Acc. Chem. Res. 1968, 1, 42-49; (d) Clow, R. P.; Futrell, J. H. Ion Cyclotron Resonance Study of the Mechanism of Chemical Ionization. Mass Spectrometry of Selected Hydrocarbons Using Methane Reagent Gas. J. Am. Chem. Soc. 1972, 94, 3748-3755. 
30. Houriet, R.; Parisod, G.; Gaumann, T. The Mechanism of Chemical Ionization of $n$-Paraffins. I. Am. Chem. Soc. 1977, 99, 3599-3602.

31. Keough, T. Dimethyl Ether as a Reagent Gas for Organic Functional Group Determination by Chemical Ionization Mass Spectrometry. Anal. Chem. 1982, 54, 2540-2547.

32. Horning, E. C.; Horning, M. G.; Carroll, D. I. Dzidic, I.; Stillwell, R. N. New Picogram Detection System Based on a Mass Spectrometer with an External Ionization Source at Atmospheric Pressure. Anal. Chem. 1973, $45,936-943$

33. Dzidic, I.; Carroll, D. I. Stillwell, R. N.; Horning, E. C. Comparison of Positive Ions Formed in Nickel-63 and Corona Discharge Ion Sources Using Nitrogen, Argon, Isobutane, Ammonia and Nitric Oxide as Reagents in Atmospheric Pressure Ionization Mass Spectrometry. Anal. Chem. 1976, 48, 1763-1768.

34. Ketkar, S. N.; Dulak, J. G.; Dheandhanoo, S.; Fite, W. L. Benzene Charge Exchange at Atmospheric Pressure for Low-Level Detection of Pollutants in Ambient Air. Anal. Chim. Acta 1991, 245, 267-270.

35. Siegel, M. W.; Fite, W. L. Terminal Ions in Weak Atmospheric Pressure Plasmas. Applications of Atmospheric Pressure Ionization to Trace Impurity Analysis in Gases. J. Phys. Chem. 1976, 80, 2871-2881.

36. Sieck, L. W.; Buckley, T. J.; Herron, J. T.; Green, D. S. Pulsed ElectronBeam Ionization of Humid Air and Humid Air/Toluene Mixtures: Time-Resolved Cationic Kinetics and Comparisons with Predictive Models. Plasma Chem. Plasma Process. 2001, 21, 441-457.

37. Lias; S. G. Ionization Energy Evaluation. In NIST Chemistry WebBook, NIST Standard Reference Database No. 69; Maillard, W. G.; Linstrom, P. J., Eds.; National Institute of Standards and Technology: Gaithersburg, MD; http://webbook.nist.gov/chemistry/, 2008.
38. Field, F. H.; Lampe, F. W. Reactions of Gaseous Ions. Hydride Transfer Reactions. J. Am. Chem. Soc. 1958, 80, 5587-5592.

39. Lias, S. G.; Eyler, J. R.; Ausloos, P. Hydride Transfer Reactions Involving Saturated Hydrocarbons and $\mathrm{CCl}_{3}{ }^{+}, \mathrm{CCl}_{2} \mathrm{H}^{+}, \mathrm{CCl}_{2} \mathrm{~F}^{+}, \mathrm{CF}_{2} \mathrm{Cl}^{+}, \mathrm{CF}_{2} \mathrm{H}^{+}$, $\mathrm{CF}_{3}{ }^{+}, \mathrm{NO}^{+}, \mathrm{C}_{2} \mathrm{H}_{5}{ }^{+}$, sec- $\mathrm{C}_{3} \mathrm{H}_{7}{ }^{+}$and $t-\mathrm{C}_{4} \mathrm{H}_{9}{ }^{+}$. Int. J. Mass Spectrom. Ion Phys. 1976, 19, 219-239.

40. Tanaka, Y. Tsuji, M. Nishimura, Y. Mass Spectrometry Study on Ion-Molecule Reactions of $\mathrm{CH}_{5}{ }^{+}, \mathrm{C}_{2} \mathrm{H}_{5}{ }^{+}$, and $\mathrm{C}_{3} \mathrm{H}_{5}{ }^{+}$with $n$-Paraffins in an Ion Trap. Bull. Chem. Soc. Jpn. 2000, 73, 2703-2712.

41. Jiao, C. Q.; DeJoseph, C. A., Jr.; Garscadden, A. Electron Impact Ionization and Ion Reactions in n-Butane. J. Phys. D Appl. Phys. 2007, 40, 409-414.

42. Williams, S.; Knighton, W. B.; Midey, A. J.; Viggiano, A. A.; Irle, S.; Wang, Q. F.; Morokuma, K. Oxidation of Alkyl Ions, $\mathrm{C}_{\mathrm{n}} \mathrm{H}_{2 \mathrm{n}+1}{ }^{+}(\mathrm{n}=$ 1-5), in Reactions with $\mathrm{O}_{2}$ and $\mathrm{O}_{3}$ in the Gas Phase. J. Phys. Chem. A 2004, 108, 1980-1989.

43. Mack, P.; Dyke, J. M.; Wright, T. G. Calculated Thermodynamics of Reactions Involving $\mathrm{NO}^{+} \cdot$ X Complexes (where $\mathrm{X}=\mathrm{H}_{2} \mathrm{O}, \mathrm{N}_{2}$ and $\mathrm{CO}_{2}$ ). Chem. Phys. 1997, 218, 243-256.

44. Lee, E. P. F.; Mack, P.; Wright, T. G. The Geometric Structure and Stability of the $\mathrm{NO}^{+} \cdot \mathrm{CH}_{4}$ Cationic Complex. Chem. Phys. 1997, 224 191-199.

45. Smith, D.; Wang, T.; Spanel, P. A SIFT Study of the Reactions of $\mathrm{H}_{2} \mathrm{ONO}^{+}$Ions with Several Types of Organic Molecules. Int. J. Mass Spectrom. 2003, 230, 1-9.

46. Field, F. H. Chemical Ionization Mass Spectrometry. VIII. Alkenes and Alkynes. J. Am. Chem. Soc. 1968, 90, 5649-5656.

47. Marotta, E.; Paradisi, C. Unpublished results. 